\title{
Image-Guided Radiotherapy Using MV for Prostate Cancer: A Correlation Analysis between Electronic Portal Imaging with Fiducial Markers and Cone Beam CT
}

\author{
Salas Buzón M del C ${ }^{* 1}$, Gutiérrez Bayard L ${ }^{1}$, Lagares-Franco $C^{2}$ and de Ingunza Barón $\mathrm{L}^{1}$ \\ ${ }^{1}$ Physician, Radiation Oncology, Integral Care Unit Cancer, Radiation Oncology Service Hospital Universitario \\ Puerta del Mar, Cádiz, Spain \\ ${ }^{2}$ Physicist, Department of Statistics and Operations Research University of Cádiz, Spain
}

${ }^{*}$ Corresponding author: Salas Buzón M del C, Physician, Radiation Oncology, Integral Care Unit Cancer, Radiation Oncology Service Hospital Universitario Puerta del Mar, Cádiz, Spain Avenida Ana de Viya 21, 11200, Cádiz, Tel: 0034 956003002, 0034 626990555, E-mail: mcsalasbuzon@gmail.com

Citation: Salas Buzón Mdel C, Gutiérrez Bayard L, Lagares-Franco C, de Ingunza Barón L (2016) ImageGuided Radiotherapy Using MV for Prostate Cancer: A Correlation Analysis between Electronic Portal Imaging with Fiducial Markers and Cone Beam CT. J Adv Radiol Med Image 1(1): 101. doi: 10.15744/24565504.1.101

Received Date: April 01, 2015 Accepted Date: July 22, 2016 Published Date: July 25, 2016

\begin{abstract}
Background: To study the reliability and agreement between electronic portal imaging (EPI) and cone beam computed tomography (CBCT) with megavoltage (MV) and fiducial markers (FM), in image-guided radiotherapy (IGRT) for prostate cancer.

Materials and Methods: A total of 40 patients with prostate cancer were enrolled in a prospective study. Before each daily session, one megavoltage ortogonal EPI in two proyection (antero-posterior and lateral) and two megavoltage cone beam computed tomography (MV $\mathrm{CBCT}$ ) images were sequentially acquired for 11 days. A total of 1,320 images from 40 patients were obtained and analyzed, of which 440 were megavoltage electronic portal images with fiducial markers (MV EPI-FM) images, 440 were megavoltage cone beam with fiducial markers (MV CBFM) images, and 440 were megavoltage cone beam soft tissue (MV CBST) images. Off-line reconstruction was performed using fiducial markers (MV CBFM) and soft tissue matching (MV CBST). To evaluate the correlation between the three imaging methods, each one was compared to the other two. The Intra-class Correlation Coefficient (ICC) was calculated and Bland-Altman analysis was performed. Value of ICC was used to assess the agreement or reliability of quantitative data for the two techniques namely displacement of the isocenter in the three spatial axes between MV EPI-FM and MV CBCT (FM or ST).

Results: Using FM matching ICC values for MV EPI-FM versus (vs.) CBFM were 0.911, 0.849, and 0.924 in the left-right (LR), superoinferior (SI) and anterior-posterior (AP) axis, respectively. Using soft tissue matching ICC values for MV EPI-FM vs. CBST were 0.767, 0.715, and 0.806 in LR, SI and AP axis. ICC values for CBFM vs. CBST were 0.795, 0.725, and 0.834 in the LR, SI and AP axis.

Conclusion: Reliability and agreement between EPI-FM and CBFM using MV images is greater, as compared to the agreement between EPI-FM and CBST, and between CBFM and CBST. Concordance as measured by the ICC was higher when fiducial markers were used.

Keywords: Image Guided Radiation Therapy; Correlation analysis; MV Cone Beam CT; Electronic portal imaging; Fiducial markers; Prostate cancer

List of Abbreviations: 3D CRT: Three-dimensional conformational radiotherapy; 2D: Two dimensions; 3D: Three dimensions; IMRT: Intensity-modulated radiation therapy; IGRT: Image guided radiotherapy; LR: Left-rigth: SI: Supero-inferior; AP: Antero-posterior; LAT: Lateral; EPI: Electronic portal Image; CBCT: Cone beam computed tomography; PTV: Planning tumor volume; MV: Megavoltage; KV: Kilovoltaje; FM: Fiducial markers; ICC: Intraclass correlation coefficient; CBFM: Cone beam with fiducial markers; CBST: Cone Beam with soft tissues; LINAC: Linear accelerator; KV CT: Kilovoltaje computed tomography; MV EPI: Electronic portal image with megavoltage; MV CBFM: Megavoltage cone beam computed tomography with fiducial markers; MV CBST: Megavoltage cone beam soft tissues; MV EPI-FM: Megavoltage electronic portal image with fiducial marker
\end{abstract}

\section{Background}

IGRT combined with three-dimensional conformal radiation therapy (3D CRT) and intensity-modulated radiation therapy (IMRT) is gaining quick acceptance in radiotherapy treatment of prostate cancer [1-4]. The advantage of this technique is that it localizes the target volume accurately, thus increasing precision in treatment delivery. Also, IGRT allows to reduce planning target volume (PTV) margins, which spares rectal and bladder toxicity and makes modern, daily-use technological tools highly reliable [5-8].

FM are used in radiotherapy for to enhance the process of identifying prostate [9-11]. Normally, FM are placed inside to the target volumes prior to the radiotherapy simulation and serve as surrogates to the target volumes [12-16]. It is hoped that the FM can be 
clearly and easily identified and localized on both simulation and verification images. An important requirement is that serve to reduce uncertainties related to the process of positioning and administration of radiotherapy [2,17] .

A condition on the use of FM is a clear identification of markers on the images without introducing a significant amount of artifacts. The reduction of artifacts on the planning CT is especially desirable, since extensive artifacts could interfere with structure delineation, dose calculation and affect the clarity of the anatomical region of interest [18].

The gold markers, are widely used in IGRT, having studied the visibility and artifacts resulting in various modalities of image [19]. After analysis of gold FM, carbon and polymers as fiducial markers on the CT images, gold markers produced a significant artifact, while no artifacts were observed with polymer markers. Also the contrast increased with KV for the gold markers, whit decreasing for the polymer and carbon marker [20,21]. If MV will be the sole imaging modality for positioning verification, it may be necessary to use gold markers despite the artifacts they create on the CT simulation images [20].

Although we cannot ignore the fact that insert FM is an invasive procedure, and that involve an economic cost and human resources [22,23], fiducial marker implantation for prostate IGRT is associated with a small percentage of patients experiencing moderate to severe complications requiring further medical interventions [24].

As usual, the FM are widely used in imaging methods $2 \mathrm{D}$ and $3 \mathrm{D}$, since they are easily visualized on EPI and KV-CBCT scans $[3,13-15,25,26]$.

Studies have been conducted comparing displacements measured by fiducial markers in 2D EPI vs. 3D KV CBCT [27-31]. But, there are no studies available comparing the accuracy of different imaging methods, for their application in IGRT, using MV linear accelerators (MV LINAC) [32,33], although this technology (KV or MV) is extensively used in our professional field [3,29,34,35].

The MV LINAC allow 2D orthogonal images systems such as electronic portal image (EPI) [36] and volumetric or 3D imaging systems, such as cone beam computed tomography (CBCT) [37,38]. Both imaging methods have different characteristics and acquisition protocols and are performed differently. However, such differences do not mean that any of these systems is superior to the other. There is no clear evidence on the best imaging method in daily clinical practice $[39,40]$, the most accurate in target localization, or the preferable method -planar or volumetric images- when an IGRT protocol is initiated for treating a prostate cancer $[30,31,41,42]$.

Both, $2 \mathrm{D}$ and $3 \mathrm{D}$ imaging systems have advantages and disadvantages, and there is no general agreement on the best method to be used in centers fitted with MV IGRT equipment [30]. It depends on the technical characteristics of the LINAC, the energy available for the acquisition of images, the use or not of FM, and the organizational reliability of each institution [29,34,37].

There are some studies conducted to assess agreement between EPI and CBCT but have different methods of assessment to ours [29-31,34,43], and performed mainly with KV energy, nevertheless there are few data quantifying the agreement between EPI and CBCT with MV energy.

Therefore, the aim of this study was quantify the reliability or reproducibility of the different imaging methods provided by a exclusive MV image device, by calculating agreement between EPI, CBFM and CBST.

\section{Methods}

The study sample was composed of 40 patients with early T1-T3a prostate adenocarcinoma included in a prospective IGRT protocol between January 2012 and June 2013. The study was approved by the Ethics Committee of the Puerta del Mar University Hospital, Cadiz, Spain.

Four $(3 \mathrm{~mm} \times 1 \mathrm{~mm})$ gold FM (Lorca Marín ${ }^{\circledR}$ ) were implanted in the prostate under trans-rectal ultrasound guidance. Treatments were delivered using the LINAC ONCOR, SIEMENS, of $6 \mathrm{MV}$. The Planning Target Volume (PTV) was defined as the prostate \pm the seminal vesicles with a $7 \mathrm{~mm}$. margin in each direction, except for a $5 \mathrm{~mm}$. posterior margin. Ninety-five percent of the dose was delivered to $95 \%$ of the target volume. Patients and treatment characteristics are presented in Table 1.

\begin{tabular}{|c|c|}
\hline No. of patients & 40 \\
\hline \multicolumn{2}{|l|}{ Age } \\
\hline Median & 68 \\
\hline Range & $52-79$ \\
\hline \multicolumn{2}{|c|}{ Radiotherapy dose (cGy) } \\
\hline Median & 7670 \\
\hline Range & $7540-7850$ \\
\hline Fraction size (cGy) & 200 \\
\hline \multicolumn{2}{|c|}{ Gleason Score (no. of patient) } \\
\hline \multicolumn{2}{|l|}{$\leq 6$} \\
\hline 7 & 37 \\
\hline$\geq 8$ & 0 \\
\hline
\end{tabular}




\begin{tabular}{|c|c|}
\hline Clinical stage (no. of patients) \\
\hline T1c & 22 \\
\hline T2a & 10 \\
\hline T2b & 1 \\
\hline T2c & 6 \\
\hline T3a & 1 \\
\hline Androgen supression (no. of patients) \\
\hline Yes & 13 \\
\hline (neoadyuvant+concurrent) & 27 \\
\hline Non & 4 \\
\hline \multicolumn{2}{|c|}{ 3D CRT } \\
\hline \multicolumn{2}{|c|}{ IMRT } \\
\hline
\end{tabular}

Abbreviations.3D CRT: 3D conformational radiotherapy; IMRT: intensitymodulated radiation therapy

Table 1: Patients and treatment characteristics

\section{Simulation}

All patients underwent bowel, colon and vesicle preparation according to an adapted protocol of Smitsmans et al. [44]. With the patients in supine position with a support under the knees and feet, CT scans (Phillips Brillance CT 64-slices, 120 Kvp, $60 \mathrm{~mA}$ ) of the pelvis were acquire with a slice thickness of $3 \mathrm{~mm}$ and a transversal pixel size of $0,65 \times 0,65 \mathrm{~mm}^{2}$. Reference points were marked on the skin. Treatment volumes, FM, bladder, rectum and femoral heads were contoured using the Virtual Simulator PCRT, version 6.0.

\section{Treatments, EPI and FM-based registration}

Patients were positioned daily using the immobilization system described above and aligned to the treatment room isocentre using skin markers. Daily pre-treatment $6 \mathrm{MV}$-EPI were acquired by antero-posterior (AP) and lateral (LAT) projection, using 2 Units Monitor (UM) in AP projection, and 3 UM in LAT projection. By means of specific ONCOR software (Coherence Therapist system Work Space 2.2.09), we performed the matching of the four FM on MV EPI AP and LAT images, which were compared with digitally reconstructed radiographs (DRR) generated from the planning CT. Shifts between image sets were calculated automatically to identify the new position of the isocenter in $\mathrm{cm}$. in the three axes. Isocenter deviations from initial tattoos (skin markers) were calculated and recorded, obtaining 1520 EPI (38 sessions per patient). For the purposes of concordance analysis, the EPI on days 1,2,3,4,5,10,15,20,25,30 and 35 were selected: 440 EPI (projections AP and LAT).

A total of 440 CBCT (29\%) were acquired in 11 sessions per patient (days 1,2,3,4,5,10,15,20,25,30 and 35) at standard dose, using 190-degree arc therapy. Thickness of reconstruction: $10 \mathrm{~mm}, 10 \mathrm{x} 10 \mathrm{~cm}$ field. Off-line reconstruction and MV-CBCT adjustment with FM (CBFM) and soft-tissue (CBST). Shifts were firstly estimated by alignment of FM on CBFM and later of soft tissues on CBST. Deviations of the isocenter were measured in the AP, SI and LR dimensions. Shifts estimated by CBCT were registered for analysis, but they were never applied to patients. The matching of the MV-EPI and MV CBFM was performed by five physicians while off-line matching of MV CBST was performed by a single physician.

With the patient immobilized, the isocenter of the treatment was immediately aligned using the shifts identified on EPI images with FM. The radiotherapist did not enter into the room. The process was performed as quickly as possible in 25 to 30 minutes.

\section{Interobserver and intraobserver study}

An interobserver study was performed to evaluate the influence of interobserver variation on FM matching with the MV CBFM image set. Because these markers are clearly visible on CBCT, they are not clearly visible on KV CT reference images due to the distortion caused by the high atomic number of gold, which causes a slight blurring of the markers and needs careful matching [18-20]. Image sets were randomly chosen from five patients selected from the 40 study patients. The interobserver study was performed by five physicians with experience using planning system alignment tools and involved in the image-guidance program. The observers performed volumetric registration using translational shifts only, to align the FM as visualized on the CBCT dataset with the FM visualized on CT reference images. The resulting isocenter shift was computed and recorded for each observer and for each dataset. To give an estimate of intraobserver variability, one observer repeated the entire FM alignment procedure 1 week later.

An intraobserver study was performed to evaluate the influence of intraobserver variation for soft tissue matching on MV-CBST following the same procedure. Both studies were conducted over a period of seven days. 


\section{Statistical Analysis}

Statistical analysis was performed using IBM SPSS Statistics 21 and the freeware EPIDAT 4.0. Quantitative variables are described as frequencies and tables. Agreement or reliability of quantitative variables are frequently assessed using Pearson's correlation coefficient (r). However, in this study the Pearson's correlation coefficient is not useful, given that two measuring tools can systematically provide different values other and obtain a perfect correlation $(r=1)$ but null reliability [45]. Therefore, Intraclass Correlation Coefficient (ICC) [46], was used to assess the agreement or reliability of quantitative data for the two techniques i.e. displacement of the isocenter in the three spatial axes between MV EPI-FM and MV CBCT (FM or ST). ICC is defined as the proportion of variance among patients and provides an objective coefficient that is especially useful when comparing two methods, as it is the case of this study.

As a rough guide, we followed the ratings suggested by Landis and Koch et al. An agreement level of $0-0.2$ was considered poor, 0.2-0 .4 fair, 0.4-0.6 moderate, 0.6-0.8 substantial, and 0.8-<1.0 almost perfect [47]. Interobserver agreement for MV EPI, MV CBFM and planning CT was calculated by the ICC in each axis, while intraobserver agreement was calculated for MV CBST (Figure 1).
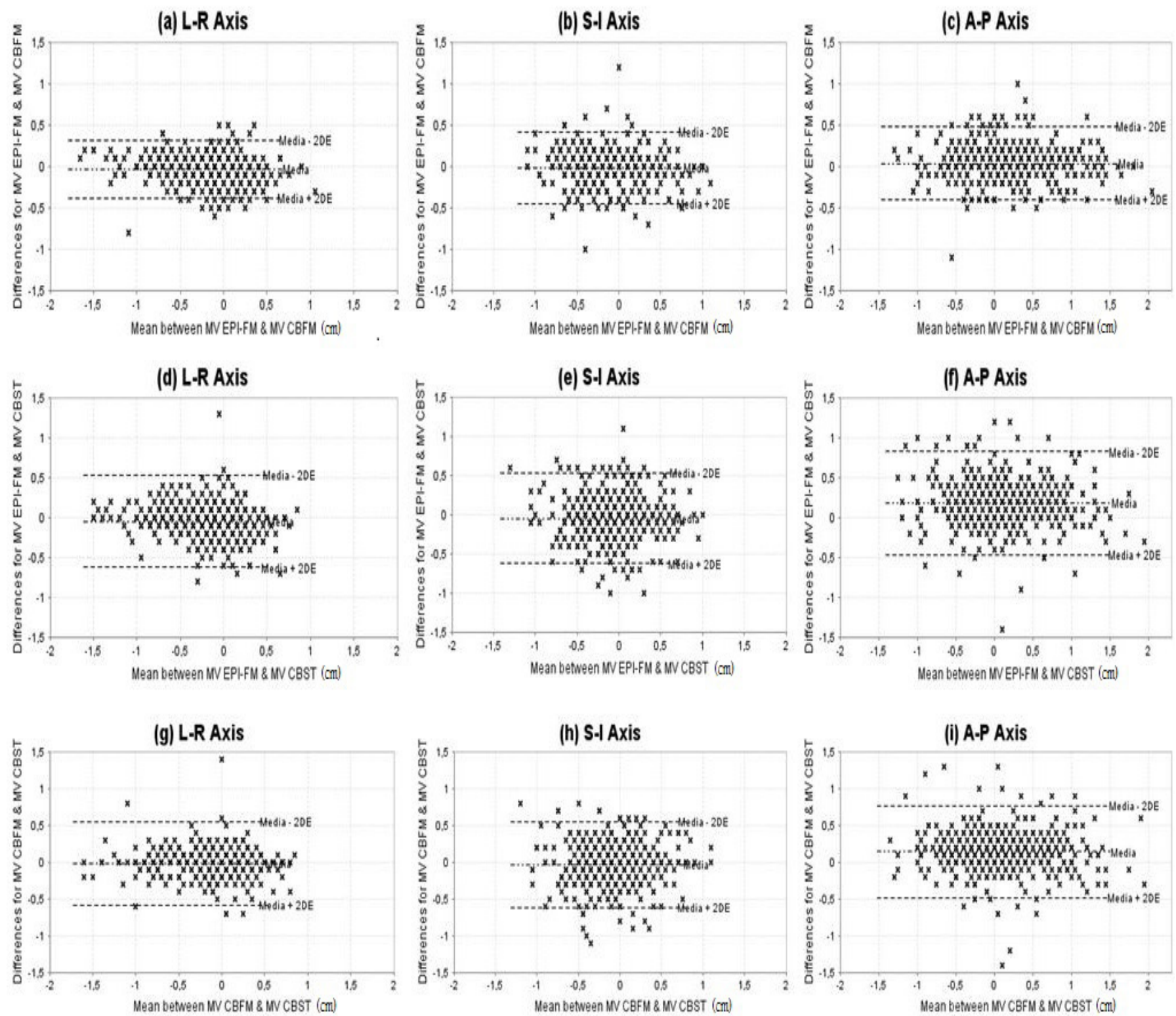

Figure 1: The difference between the imaging modalities as a function of the mean value of FM and soft tissues (prostate), in cm. The dashed lines show the media +/- 2 SD in each plane. (a-c) MV FM vs. MV CBFM; (d-f) MV FM vs. MV CBST; (g-i) MV CBFM vs. MV CBST

The difference between measured couch shifts was then plotted against the average couch shift as recommended by Bland and Altman [48] when new methods of measurement emerge. The 95\% confidence interval (CI) of the error distribution is also reported. The percentage of shifts within a $\pm 3 \mathrm{~mm}$ and $\pm 5 \mathrm{~mm}$ tolerance was calculated for the three techniques, in order to make a comparison with previous concordance studies. The frequency of differences between measurements in each plane was calculated and represented graphically (Figure 2). 

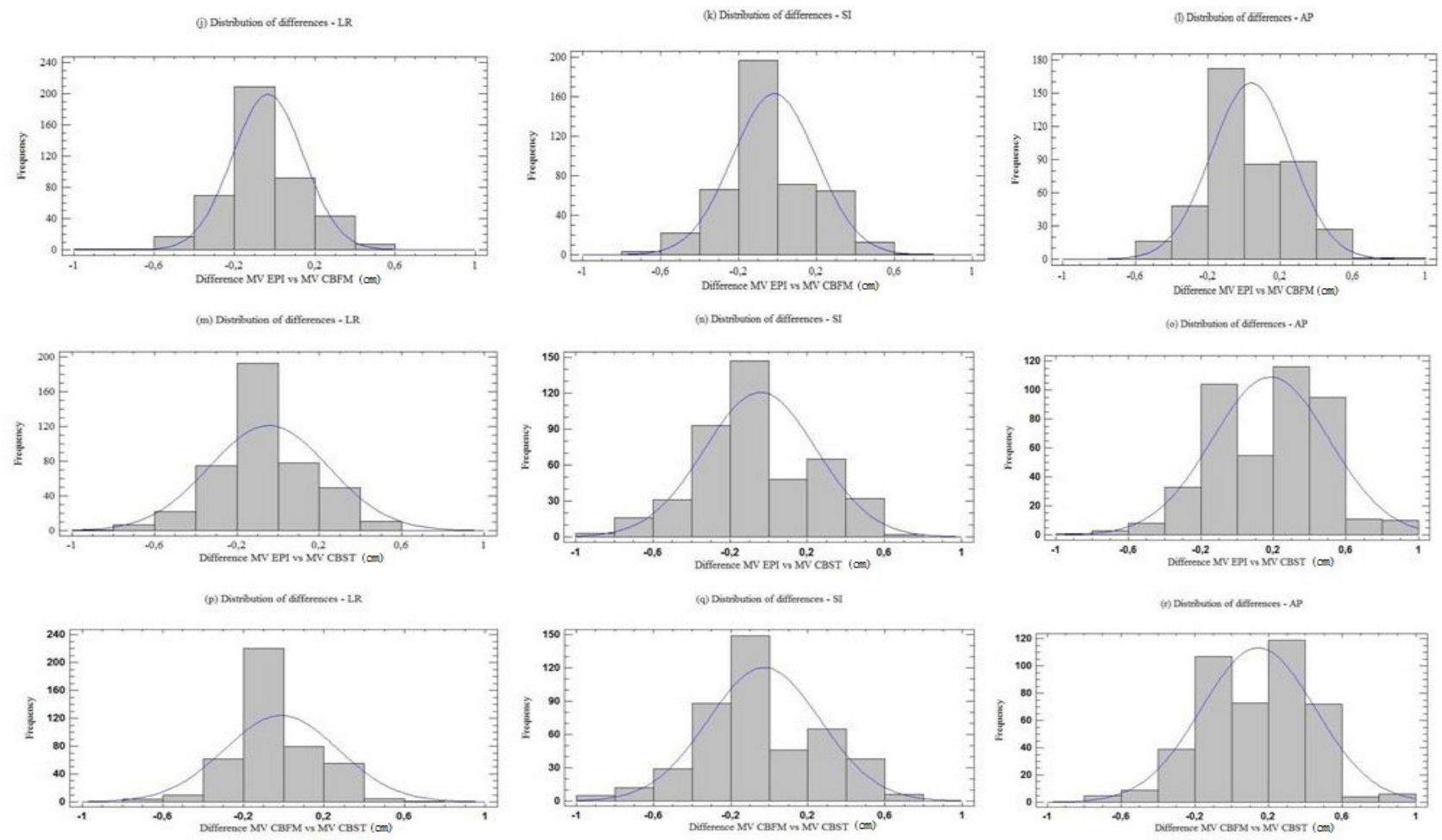

Figure 2: Frequency of differences in cm. occurring between shifts according to the method and each axis. (j-1) MV FM vs. MV CBFM; (m-o) MV FM vs. MV CBST; (p-r) MV CBFM vs. MV CBST.

\section{Results}

A total of 1,320 images from 40 patients were obtained and analyzed, of which 440 were MV EPI-FM images, 440 were MV CBFM images and 440 were MV CBST images. All shifts resulting from the EPIs were applied to each session. Each EPI delivered 2 UM per image AP and 3 UM per image LAT. The CBCT delivered $10 \mathrm{cGy}$ per scan. MV CBST matching was performed with soft-tissue and ignoring FM.

\section{Intraclass Correlation Coefficient between the three methods}

To evaluate the correlation between the three imaging method, each one was compared to the other two. As summarized in Table 2, ICC values are shown along with their corresponding 95\% CI and significance values for all three axis. We found an "almost perfect” strength of agreement between MV EPI-FM and MV CBFM in LR, SI and AP, as well as between MV EPI and MV CBST and between MV CBFM and MV CBST.

\begin{tabular}{|c|c|c|c|c|c|c|}
\hline \multicolumn{4}{|c|}{ Intra class Correlation Coefficient and 95\% Confidence Interval } & \multicolumn{2}{|c|}{ Significancerelative to 0} & \multirow[b]{2}{*}{ AP } \\
\hline & LR & SI & AP & LR & SI & \\
\hline $\begin{array}{l}\text { MV EPI-FM vs. } \\
\text { MV CBFM }\end{array}$ & $\begin{array}{c}0.911 \\
(0.891-0.927)\end{array}$ & $\begin{array}{c}0.849 \\
(0.820-0.873)\end{array}$ & $\begin{array}{c}0.924 \\
(0.908-0.932)\end{array}$ & $\begin{array}{l}F: 22.081 \\
p<0.0001\end{array}$ & $\begin{array}{l}F: 22.081 \\
p<0.0001\end{array}$ & $\begin{array}{l}F: 26.195 \\
p<0.0001\end{array}$ \\
\hline $\begin{array}{c}\text { MV EPI-FM vs. } \\
\text { MV CBST }\end{array}$ & $\begin{array}{c}0.767 \\
(0.725-0.804) \\
\end{array}$ & $\begin{array}{c}0.715 \\
(0.665-0.759) \\
\end{array}$ & $\begin{array}{c}0.806 \\
(0.633-0.884) \\
\end{array}$ & $\begin{array}{c}F: 7.740 \\
p<0.0001\end{array}$ & $\begin{array}{c}F: 6.125 \\
p<0.0001\end{array}$ & $\begin{array}{l}F: 12.003 \\
p<0.0001\end{array}$ \\
\hline $\begin{array}{l}\text { MV CBFM vs. } \\
\text { MV CBST }\end{array}$ & $\begin{array}{c}0.795 \\
(0.758-0.827)\end{array}$ & $\begin{array}{c}0.725 \\
(0.678-0.767)\end{array}$ & $\begin{array}{c}0.834 \\
(0.731-889)\end{array}$ & $\begin{array}{c}F: 8.752 \\
p<0.0001\end{array}$ & $\begin{array}{c}F: 6.313 \\
p<0.0001\end{array}$ & $\begin{array}{l}F: 13.158 \\
p<0.0001\end{array}$ \\
\hline
\end{tabular}

Abbreviations: LR: Lateral; SI: Supero-inferior; AP: Antero-posterior; MV EPI-FM: Megavoltage electronic portal image with fiducial markers; MV CBFM: Megavoltage cone beam computed tomography with fiducial markers; MV CBST: Megavoltage cone beam soft tissues Table 2: Results of Intraclass Correlation Coefficient between three methods

\section{Bland-Altman Analysis}

Figure 1 shows the results of the Bland-Altman analysis for the three techniques. The average differences between MV EPI-FM and MV CBFM were: -0.0330 (95\% CI.: - 0.0495, -0.0164), -0.0164 (95\%CI.: -0.0365, +0.0038), 0.0402 (95\%CI: +0.0196+0.0609) in the LR, SI and AP axis respectively (Figure 1a-c). Between MV EPI-FM and MV CBST: -0.0445 (95\%CI.: -0.0717, -0.0174), -0.0430 (95\%CI.: $-0.0702,-0.0157), 0.1845$ (95\%CI: $+0.1543,+0.2148)$ in the LR, SI and AP axis (Figure 1.d-f). Between MV CBFM and MV CBST: -0.0116 (95\%CI.: -0.0381, +0.0150), -0.0266 (95\%CI.: -0.0539, +0.0008), 0.1443 (95\%CI: +0.1153, +0.1734) in the LR, SI and AP axis (Figure 1g-i).

Table 3 Shows the percentage of shift differences within a $\pm 3 \mathrm{~mm}$. and $\pm 5 \mathrm{~mm}$ 


\begin{tabular}{|c|c|c|c|}
\hline \multirow{3}{*}{ LATERAL } & Method & $\mathbf{\pm 3 m m}$ & $\mathbf{\pm 5 m m}$ \\
\cline { 2 - 4 } & MV EPI-FM vs. MV CBFM & $94.5 \%$ & $99.5 \%$ \\
\cline { 2 - 4 } & MV-EPI-FM vs. MV CBST & $89.8 \%$ & $97 \%$ \\
\hline \multirow{3}{*}{ LONGITUDINAL } & MV CBFM vs. MV CBST & $94.1 \%$ & $97.7 \%$ \\
\cline { 2 - 4 } & MV EPI-FM vs. MV CBFM & $89.5 \%$ & $98.2 \%$ \\
\cline { 2 - 4 } & MV EPI-FM vs. MV CBST & $80.2 \%$ & $92.3 \%$ \\
\hline \multirow{2}{*}{ VERTICAL } & MV CBFM vs. MV CBST & $79.1 \%$ & $93.2 \%$ \\
\cline { 2 - 4 } & MV EPI-FM vs. MV CBFM & $90.7 \%$ & $97 \%$ \\
\cline { 2 - 4 } & MV EPI-FM vs. MV CBST & $70 \%$ & $90.2 \%$ \\
\hline
\end{tabular}

Abbreviations: MV EPI-FM: Megavoltage electronic portal image with fiducial markers; MV CBFM: Megavoltage cone beam computed tomography with fiducial markers; MV CBST: Megavoltage cone beam computed tomography soft tissues

Table 3: Percentage of shifts within a \pm 3 and $\pm 5 \mathrm{~mm}$ differences

\section{Inter and intraobserver Intraclass Correlation Coeficient}

The interobserver ICC for the LR axis was 0.963 (95\% CI.: 0.874 - 0.996); 0.958 (IC 95\%: 0.856 - 0.995) for the SI axis, and 0.978 (IC 95\%: 0.922 - 0.997) for the AP axis, interpreting the strength of agreement as "almost perfect" in the three axis. All physicians had a minimum of six month experience in MV CBFM matching. The intraobserver ICC for the LR axis was 0.960 (95\% CI.: 0.871 - 0.997); 0.956 (IC 95\%: 0.860 - 0.990) for the SI axis, and 0.972 (IC 95\%: 0.990 - 0.998) for the AP axis, interpreting the strength of agreement as "almost perfect" in the three axis.

\section{Frequency of differences}

Figure 2 shows histograms of the frequency of differences between shifts in each technique in each axis.

\section{Discussion}

To the extent of our knowledge, there are no previous studies comparing agreement between MV energy and FM imaging methods used before treatment and sequentially in the same patient. Such lack of literature is surprising, considering the large number of institutions that use MV IGRT exclusively.

We evaluated agreement between planar systems and MV volumetric systems using EPI images with FM, since according to numerous studies, it is a valid reference method in IGRT [11,15,16,41,49-51]. As alternative methods, we used CBCT with fiducials and CBCT with soft-tissue. Table 4 summarizes the studies assessing agreement between IGRT methods with FM and transponders.

\begin{tabular}{|c|c|c|c|c|c|c|c|}
\hline Author & Year & No. Patients & Energy & No. Dataset & Comparison & Objetive & Conclusion \\
\hline $\begin{array}{l}\text { Langen KM. et al. } \\
\text { [37] }\end{array}$ & 2005 & 3 patients & $\begin{array}{l}\text { MVCT with } \\
\text { KVCT images } \\
\text { (planification) }\end{array}$ & 120 & $\begin{array}{l}\text { Marker, ana- } \\
\text { tomical and } \\
\text { contour using } \\
\text { MVCT }\end{array}$ & $\begin{array}{l}\text { Asses three } \\
\text { techniques } \\
\text { with MV- } \\
\text { CBCT }\end{array}$ & $\begin{array}{l}\text { The use of FM in MVCT is ven- } \\
\text { tajous to reduce the inter-user } \\
\text { variability of image registration. } \\
\text { Markers based registration to } \\
\text { be more accurate than the other } \\
\text { techniques. }\end{array}$ \\
\hline $\begin{array}{l}\text { Moseley DJ et al. } \\
{[21]}\end{array}$ & 2007 & 15 patients & $\begin{array}{l}\text { MV-EPI FM } \\
\text { KV-CBFM } \\
\text { KV-CBST }\end{array}$ & 547 & $\begin{array}{l}\text { MV-EPI FM } \\
\text { vs. CBCT-FM } \\
\text { MV-EPI FM } \\
\text { vs. CBCT-ST }\end{array}$ & $\begin{array}{l}\text { Determining } \\
\text { the equiva- } \\
\text { lence of two } \\
\text { methods to } \\
\text { determine the } \\
\text { isocenter cor- } \\
\text { rections }\end{array}$ & $\begin{array}{l}\text { Cone-beam CT is an accurate } \\
\text { and precise tool for image } \\
\text { guidance. It provides equivalent } \\
\text { means of patient setup correc- } \\
\text { tion for prostate patients with } \\
\text { implanted gold fiducial markers. }\end{array}$ \\
\hline $\begin{array}{l}\text { Gayou O. et al. } \\
{[36]}\end{array}$ & 2008 & $\begin{array}{l}19,17 \text { and } 12 \\
\text { patients }\end{array}$ & $\begin{array}{l}\text { US; } \\
\text { MV-CBST; } \\
\text { MV PI-FM }\end{array}$ & $\begin{array}{l}696 \text { vs. } 598 \\
\text { vs. } 393\end{array}$ & $\begin{array}{l}\text { US. vs. MV- } \\
\text { CBCT vs. } \\
\text { PIFM }\end{array}$ & $\begin{array}{l}\text { Analyzed } \\
\text { couch align- } \\
\text { ments to cal- } \\
\text { culate margins } \\
\text { based on the } \\
\text { three methods } \\
\text { (IMRT) }\end{array}$ & $\begin{array}{l}\text { MV-CBCT and FM localization } \\
\text { suggest smaller variability. }\end{array}$ \\
\hline $\begin{array}{l}\text { Owen R. et al. } \\
\text { [38] }\end{array}$ & 2009 & 8 patients & $\begin{array}{l}\text { In-room CT; } \\
\text { KV-EPI }\end{array}$ & 254 & $\begin{array}{l}\text { CT on rails } \\
\text { and electronic } \\
\text { portal image } \\
\text { (EPI) radio- } \\
\text { graph }\end{array}$ & $\begin{array}{l}\text { Agreement } \\
\text { between in- } \\
\text { room CT on } \\
\text { rails and EPI } \\
\text { radiograph }\end{array}$ & $\begin{array}{l}\text { Found significant differences } \\
\text { between in-room CT and elec- } \\
\text { tronic portal imaging }\end{array}$ \\
\hline
\end{tabular}




\begin{tabular}{|c|c|c|c|c|c|c|c|}
\hline Author & Year & No. Patients & Energy & No. Dataset & Comparison & Objetive & Conclusion \\
\hline $\begin{array}{l}\text { Ogunleye P. et al. } \\
\text { [39] }\end{array}$ & 2009 & $\begin{array}{l}30 \text { Phantom } \\
\text { measures and } \\
259 \text { patients } \\
\text { measurements }\end{array}$ & KV images & $\begin{array}{l}30 \text { Phantom } \\
\text { measures } \\
\text { and } 259 \\
\text { patients } \\
\text { measure- } \\
\text { ments }\end{array}$ & $\begin{array}{l}\text { Electronic } \\
\text { tranponder/ } \\
\text { Calypso 4D } \\
\text { vs. OBI-KV } \\
\text { Image }\end{array}$ & $\begin{array}{l}\text { Correlation of } \\
\text { three systems }\end{array}$ & $\begin{array}{l}\text { Good correlation between } \\
\text { Calypso and OBI }\end{array}$ \\
\hline $\begin{array}{l}\text { Barney M. et al. } \\
\text { [20] }\end{array}$ & 2010 & 36 patients & $\begin{array}{l}\text { KV-PIFM; } \\
\text { KV-CBST }\end{array}$ & 1244 vs. 286 & $\begin{array}{l}\text { KV-PIFM vs. } \\
\text { KV-CBST }\end{array}$ & $\begin{array}{l}\text { Comparing } \\
\text { fiducial mark- } \\
\text { ers and CBCT } \\
\text { for dairy } \\
\text { localization of } \\
\text { prostate }\end{array}$ & $\begin{array}{l}\text { Cone-beam computed tomogra- } \\
\text { phy and KV fiducial imaging are } \\
\text { similar; however, more than one } \\
\text { fourth of CBCT and KV shifts } \\
\text { differed enough to affect target } \\
\text { coverage. }\end{array}$ \\
\hline $\begin{array}{l}\text { Logadottir A. et } \\
\text { al. [17] }\end{array}$ & 2011 & 20 patients & $\begin{array}{l}\text { KV-CBCT; } \\
\text { KV-PIFM }\end{array}$ & Unspecified & $\begin{array}{l}\text { KV-FM (OBI) } \\
\text { vs.KV-FM } \\
\text { (Exatrac) and } \\
\text { KV-FM vs. } \\
\text { KV-CBCT }\end{array}$ & $\begin{array}{l}\text { Positional } \\
\text { uncertainties } \\
\text { related to set- } \\
\text { up of prostate: } \\
\text { using 2D-2D } \\
\text { and } 3 \mathrm{D} \text { images }\end{array}$ & $\begin{array}{l}\text { The precision of the } 2 \mathrm{D}-2 \mathrm{D} \text { set- } \\
\text { up is equivalent to the precision } \\
\text { of the } 3 \mathrm{D} \text { images. Soft-tissue } \\
\text { based set-up needs } 1 \mathrm{~mm} \text { larger } \\
\text { set-up margins. }\end{array}$ \\
\hline $\begin{array}{l}\text { Foster RD. et al. } \\
\text { [19] }\end{array}$ & 2012 & $\begin{array}{l}21 \text { and } 6 \\
\text { patients }\end{array}$ & $\begin{array}{l}\text { KV-FM (Ca- } \\
\text { lypso); } \\
\text { KV-CBCT } \\
\text { (Calypso) }\end{array}$ & $\begin{array}{l}915 \text { CBCT } \\
\text { and } 260 \\
\text { OBI }\end{array}$ & $\begin{array}{l}\text { KV-OBI vs. } \\
\text { Calypso 4D } \\
\text { KV-CBCT vs. } \\
\text { Calypso 4D }\end{array}$ & $\begin{array}{l}\text { Comparison of } \\
\text { three systems }\end{array}$ & $\begin{array}{l}\text { Localizations with CBCT/KV } \\
\text { imaging and the Calypso system } \\
\text { indicating excellent agreement. }\end{array}$ \\
\hline $\begin{array}{l}\text { Salas C. } \\
\text { Present study }\end{array}$ & 2014 & 40 patients & $\begin{array}{l}\text { MV EPI-FM; } \\
\text { MV CBCT }\end{array}$ & $\begin{array}{l}418 \text { each } \\
\text { method }\end{array}$ & $\begin{array}{l}\text { MV FM } \\
\text { vs.MV CBFM } \\
\text { vs. MV CBST }\end{array}$ & $\begin{array}{l}\text { Correlation of } \\
\text { three systems }\end{array}$ & $\begin{array}{l}\text { The MV CBCT provides excel- } \\
\text { lent agreement and reliability if } \\
\text { we use FM. }\end{array}$ \\
\hline
\end{tabular}

Abbreviations: MVCT: Megavoltaje CT; KVCT:Kilovoltaje CT; KV-CBST:Kilovoltaje cone beam computed tomography with soft tissues; MV EPIFM:Megavoltaje electronic portal image with fiducial markers; US: Ultrasound; MV-CBST:Megavoltaje cone beam CT soft tissues; MV-PIFM:Mega voltaje portal image with fiducial markers; KV images:Kilovoltaje images; OBI: On board images; KV-PIFM:Kilovoltaje portal image with fiducial markers; KVCBCT:Kilovoltaje cone beam computed tomography; KV-FM:Kilovoltajefiducial markers; MV CBFM:Megavoltaje cone beam CT with fiducial markers

Table 4: Comparison studies agreement between IGRT methods with fiducials

Agreement between planar and volumetric imaging techniques with FM and ST registration

The highest coefficient of concordance (ICC) was found between MV-FM EPI and MV CBFM: 0.911, 0.849, 0.924 in the LR, SI and AP axes respectively, which is an "almost perfect" agreement, similar to that reported in previous studies [31,34]. Moseley et al. reported a Pearson's correlation coefficient of $0.95,0.81$, and 0.84 in the LD, SI, and AP dimensions between MV and KV using FM, and 0.90, 0.49 and 0.51 respectively using soft tissue [34]. Foster el al. reported high coefficients of concordance between $\mathrm{kV}$ imaging systems, CBCT and the Calypso-4D system. Although the mean of mismatches among the three methods was lower than $0.8 \mathrm{~mm}$, Foster observed more uncertainty in prostate localization by CBCT as compared to 2D orthogonal images, although such differences were not clinically significant [31].

In our study, interobserver variability in MV CBFM did not have any impact on agreement among images. According to the ICC values obtained for the five observers, agreement was excellent. And it was so despite the potential difficulty involved in seed matching due to sligth distortion and artifacts caused on gold seeds on reference CT [18-20], which is more dramatic in the LR and SI dimensions. The high agreement observed demonstrates that the MV CBCT system has millimeter accuracy and precision when localizing unambiguous objects such as FM [25].

Analyzing the possible impact of the size of the FM used, we do not believe to be significant. DeLangen et al, and Chan et al, investigated a large number of commercial FM including solid gold, gold coil, and polymer types, in various imaging IGRT modalities. They found that solid markers were preferred in EPI, that only the large diameter markers are visible in MV, that the marker measuring $0,9 \mathrm{~mm}$ x $5 \mathrm{~mm}$ appears to be clinically optimal in pelvic radiotherapy patients (80\% visualization success in lateral EPID) $[18,52]$ and visibility of gold coils of $0,75 \mathrm{~mm}$ diameter or larger is comparable across all imaging modalities studied.

When the planar or volumetric system was compared with CBST, agreement diminished in the three axes. Agreement was lower in the LR and SI axes, and higher in the AP axis, where agreement was "almost perfect". When comparing the two volumetric imaging methods, the results obtained are very similar, with higher agreement in the AP axis. There is an explanation to such results, since although the quality of MV images is lower than that of KV images [53], the interface and gray gradients on rectum and prostate tissue MV images (often with gas inside) and prostate and seminal vesicle tissue images is higher as compared to the interface and gray gradients on prostate and peripheral prostate tissue images in the LR axis [37,43], and on prostate and penile bulb tissue images, in the SI axis. The quality of the image is also deleterious to the reproducibility of IGRT based on soft-tissue, which could increase interobserver variability [53]. Langen et al. stated that 3D data delivered by CBCT images may hinder the localization of the prostate, as it adds more uncertainty than two $2 \mathrm{D}$ orthogonal images. In addition, reported that FM are more advantageous and accurate, which would reduce inter-user variability [54]. 
We reviewed the studies available comparing EPI with CBCT based on FM/electromagnetic transponders and observed that most studies were performed with KV energy and yielded higher percentages of concordance when using FM/transponders than when using volumetric images without markers $[29,34,54]$.

If the rotation of the prostate is not considered, only Logadottir et al. reported similar position uncertainties when comparing 2D/3D techniques based on FM and KV soft-tissue for patient positioning, soft-tissue requiring only a $1 \mathrm{~mm}$ higher positioning margin [30].

The highest percentage of shifts within a $\pm 3 \mathrm{~mm}$. differences was between EPI-FM and CBFM: $94.5 \%, 89.5 \%$ and $90.7 \%$ in LR, SI and AP directions, as compared to CBST, which is in agreement with the results obtained by Moseley et al. [34] and Foster et al [31] and slightly lower in the SI axis. The CT slice thickness also adds to the uncertainty inherent to localization by CBCT, as compared to 2D localization based on FM. In our study, CT slice thickness was $3 \mathrm{~mm}$. Slices of lower thickness such as 2.5 $\mathrm{mm}$.[34], or $1 \mathrm{~mm}$. [31], would improve precision, since a better resolution in the SI direction would increase the precision of CBMF scans in this axis.

A limitation to this study is that FM was visible during off-line reconstruction of CBST, which was performed by a single physician. As FM could not be suppressed using any software, the strategy used was to initiate matching by bone references and then by prostate soft tissues, ignoring FM. We are aware that this could lead to bias, therefore, concordance results in matching based on CBST would be considered cautiously. This bias was unavoidable, since we wanted to assess agreement among MV imaging techniques prior to delivering the treatment to each patient.

This study contributes useful comparative data on the effectiveness of MV in IGRT that could be used in the selection of the most appropriate imaging method for positioning patients with prostate cancer prior to the treatment.

\section{Conclusions}

The precision, agreement and reliability of IGRT based on MV imaging for the localization of the prostate is similar among EPI and CBCT based on FM. The lower precision or reliability observed in the absence of FM could be due to the lower quality on MV CBCT images localizing soft tissues, which have a higher impact on the shifts observed. It is true that el use of soft tissue resulted in greater discrepancy, but the difference is clinically insignificant. The difference between MV CBFM and MV CBST was less than $2 \mathrm{~mm}$ in any direction. Considering the PTV margin, it is safe to use soft tissue for guidance to ensure adequate coverage.

\section{References}

1. Sheets NC, Goldin GH, Meyer AM, Wu Y, Chang Y, et al. (2012) Intensity-modulated radiation therapy, proton therapy, or conformal radiation therapy and morbidity and disease control in localized prostate cancer. JAMA 307: 1611-20.

2. Wu J, Haycocks T, Alasti H, Ottewell G, Middlemiss N, et al. (2001) Positioning errors and prostate motion during conformal prostate radiotherapy using on-line isocentre set-up verification and implanted prostate markers. Radiother Oncol 61: 127-33.

3. Crehange G, Martin E, Supiot S, Chapet O, Mazoyer F, et al. (2012) Image-guided radiotherapy in prostate cancer: concepts and implications. Cancer Radiother 16: $430-8$

4. Zelefsky MJ, Kollmeier M, Cox B, Fidaleo A, Sperling D, et al. (2012) Improved clinical outcomes with high-dose image guided radiotherapy compared with non-IGRT for the treatment of clinically localized prostate cancer. Int J Radiat Oncol Biol Phys 84: 125-9.

5. Jaffray DA (2007) Image-guided radiation therapy: from concept to practice. Semin Radiat Oncol 17: 243-4.

6. Martin JM, Bayley A, Bristow R, Chung P, Gospodarowicz M, et al. (2009) Image guided dose escalated prostate radiotherapy: still room to improve. Radiat Oncol 4: 50.

7. Sveistrup J, af Rosenschold PM, Deasy JO, Oh JH, Pommer T, et al. (2014) Improvement in toxicity in high risk prostate cancer patients treated with imageguided intensity-modulated radiotherapy compared to 3D conformal radiotherapy without daily image guidance. Radiat Oncol 9: 44.

8. Kok D, Gill S, Bressel M, Byrne K, Kron T, et al. (2013) Late toxicity and biochemical control in 554 prostate cancer patients treated with and without dose escalated image guided radiotherapy. Radiother Oncol 107: 140-6.

9. Kupelian PA, Willoughby TR, Meeks SL, Forbes A, Wagner T, et al. (2005) Intraprostatic fiducials for localization of the prostate gland: monitoring intermarker distances during radiation therapy to test for marker stability. Int J Radiat Oncol Biol Phys 62: 1291-6.

10. Kotte AN, Hofman P, Lagendijk JJ, van Vulpen M, van der Heide UA (2007) Intrafraction motion of the prostate during external-beam radiation therapy: analysis of 427 patients with implanted fiducial markers. Int J Radiat Oncol Biol Phys 69: 419-25.

11. Kupelian PA, Langen KM, Willoughby TR, Zeidan OA, Meeks SL (2008) Image-guided radiotherapy for localized prostate cancer: treating a moving target. Semin Radiat Oncol 18: 58-66.

12. Alasti H, Petric MP, Catton CN, Warde PR (2001) Portal imaging for evaluation of daily on-line setup errors and off-line organ motion during conformal irradiation of carcinoma of the prostate. Int J Radiat Oncol Biol Phys 49: 869-84.

13. Chung PW, Haycocks T, Brown T, Cambridge Z, Kelly V, et al. (2004) On-line aSi portal imaging of implanted fiducial markers for the reduction of interfraction error during conformal radiotherapy of prostate carcinoma. Int J Radiat Oncol Biol Phys 60: 329-34.

14. Chen J, Lee RJ, Handrahan D, Sause WT (2007) Intensity-modulated radiotherapy using implanted fiducial markers with daily portal imaging: assessment of prostate organ motion. Int J Radiat Oncol Biol Phys 68: 912-9.

15. Graf R, Wust P, Budach V, Boehmer D (2009) Potentials of on-line repositioning based on implanted fiducial markers and electronic portal imaging in prostate cancer radiotherapy. Radiat Oncol 4: 13.

16. Skarsgard D, Cadman P, El-Gayed A, Pearcey R, Tai P, et al. (2010) Planning target volume margins for prostate radiotherapy using daily electronic portal imaging and implanted fiducial markers. Radiat Oncol 5: 52. 
17. Gill S, Thomas J, Fox C, Kron T, Thompson A, et al. (2012) Electronic portal imaging vs kilovoltage imaging in fiducial marker image-guided radiotherapy for prostate cancer: an analysis of set-up uncertainties. Br J Radiol 85: 176-82.

18. Chan MF, Cohen GN, Deasy JO (2014) Qualitative Evaluation of Fiducial Markers for Radiotherapy Imaging. Technol Cancer Res Treat.

19. Habermehl D, Henkner K, Ecker S, Jakel O, Debus J, Combs SE (2013) Evaluation of different fiducial markers for image-guided radiotherapy and particle therapy. J Radiat Res 1: i61-8.

20. Handsfield LL, Yue NJ, Zhou J, Chen T, Goyal S (2012) Determination of optimal fiducial marker across image-guided radiation therapy (IGRT) modalities: visibility and artifact analysis of gold, carbon, and polymer fiducial markers. J Appl Clin Med Phys 13: 3976.

21. Van der Wielen GJ, Mutanga TF, Incrocci L, Kirkels WJ, Vasquez Osorio EM, et al. (2008) Deformation of prostate and seminal vesicles relative to intraprostatic fiducial markers. Int J Radiat Oncol Biol Phys 72: 1604-11.

22. Gill S, Li J, Thomas J, Bressel M, Thursky K, et al. (2012) Patient-reported complications from fiducial marker implantation for prostate image-guided radiotherapy. Br J Radiol 85: 1011-17.

23. Deegan T, Owen R, Holt T, Fielding A, Biggs J, et al. (2015) Assessment of cone beam CT registration for prostate radiation therapy: fiducial marker and soft tissue methods. J Med Imaging Radiat Oncol 59: 91-8.

24. Loh J, Baker K, Sridharan S, Greer P, Wratten C, et al. (2015) Infections after fiducial marker implantation for prostate radiotherapy: are we underestimating the risks? Radiat Oncol 10: 38.

25. Shi W, Li JG, Zlotecki RA, Yeung A, Newlin H, et al. (2011) Evaluation of kV cone-beam ct performance for prostate IGRT: a comparison of automatic grey-value alignment to implanted fiducial-marker alignment. Am J Clin Oncol 34: 16-21.

26. Das S, Liu T, Jani AB, Rossi P, Shelton J, et al. (2014) Comparison of Image-guided Radiotherapy Technologies for Prostate Cancer. Am J Clin Oncol 37: 616-23. 27. Owen R, Kron T, Foroudi F, Milner A, Cox J, et al. (2009) Comparison of CT on rails with electronic portal imaging for positioning of prostate cancer patients with implanted fiducial markers. Int J Radiat Oncol Biol Phys 74: 906-12.

28. Ogunleye T, Rossi PJ, Jani AB, Fox T, Elder E (2009) Performance evaluation of Calypso 4D localization and kilovoltage image guidance systems for interfraction motion management of prostate patients. Scientific World Journal 9: 449-58.

29. Barney BM, Lee RJ, Handrahan D, Welsh KT, Cook JT, et al. (2011) Image-guided radiotherapy (IGRT) for prostate cancer comparing kV imaging of fiducial markers with cone beam computed tomography (CBCT). Int J Radiat Oncol Biol Phys 80: 301-5.

30. Logadottir A, Korreman S, Petersen PM (2011) Comparison of the accuracy and precision of prostate localization with 2D-2D and 3D images. Radiother Oncol 98: $175-80$.

31. Foster RD, Pistenmaa DA, Solberg TD (2012) A comparison of radiographic techniques and electromagnetic transponders for localization of the prostate. Radiat Oncol 7: 101.

32. Morin O, Gillis A, Chen J, Aubin M, Bucci MK, et al. (2006) Megavoltage cone-beam CT: system description and clinical applications. Med Dosim 31: 51-61.

33. Pouliot J, Aubin M, Langen KM, Liu YM, Pickett B, et al. (2003) (Non)-migration of radiopaque markers used for on-line localization of the prostate with an electronic portal imaging device. Int J Radiat Oncol Biol Phys 56: 862-6.

34. Moseley DJ, White EA, Wiltshire KL, Rosewall T, Sharpe MB, et al. (2007) Comparison of localization performance with implanted fiducial markers and conebeam computed tomography for on-line image-guided radiotherapy of the prostate. Int J Radiat Oncol Biol Phys 67: 942-53.

35. Palombarini M, Mengoli S, Fantazzini P, Cadioli C, Degli Esposti C, et al. (2012) Analysis of inter-fraction setup errors and organ motion by daily kilovoltage cone beam computed tomography in intensity modulated radiotherapy of prostate cancer. Radiat Oncol 7: 56.

36. Beltran C, Herman MG, Davis BJ (2008) Planning target margin calculations for prostate radiotherapy based on intrafraction and interfraction motion using four localization methods. Int J Radiat Oncol Biol Phys 70: 289-95.

37. Bylund KC, Bayouth JE, Smith MC, Hass AC, Bhatia SK, et al. (2008) Analysis of interfraction prostate motion using megavoltage cone beam computed tomography. Int J Radiat Oncol Biol Phys 72: 949-56.

38. Korreman S, Rasch C, McNair H, Verellen D, Oelfke U, et al. (2010) The European Society of Therapeutic Radiology and Oncology-European Institute of Radiotherapy (ESTRO-EIR) report on 3D CT-based in-room image guidance systems: a practical and technical review and guide. Radiother Oncol 94: 129-44.

39. Oldham M, Letourneau D, Watt L, Hugo G, Yan D et al. (2005) Cone-beam-CT guided radiation therapy: A model for on-line application. Radiother Oncol 75: $271-8$.

40. Louvel G, Cazoulat G, Chajon E, Le Maître A, Simon A, et al. (2012) Image-guided and adaptive radiotherapy. Cancer Radiother 16: 423-9.

41. Duffton A, McNee S, Muirhead R, Alhasso A (2012) Clinical commissioning of online seed matching protocol for prostate radiotherapy. Br J Radiol 85: e127381.

42. Oehler C, Lang S, Dimmerling P, Bolesch C, Kloeck S, et al. (2014) PTV margin definition in hypofractionated IGRT of localized prostate cancer using cone beam CT and orthogonal image pairs with fiducial markers. Radiat Oncol 9: 229.

43. Gayou O, Miften M (2008) Comparison of mega-voltage cone-beam computed tomography prostate localization with online ultrasound and fiducial markers methods. Med Phys 35: 531-8.

44. Smitsmans MH, Pos FJ, de Bois J, Heemsbergen WD, Sonke JJ, et al. (2008) M : The influence of a dietary protocol on cone beam CT-guided radiotherapy for prostate cancer patients. Int J Radiat Oncol Biol Phys 71: 1279-86.

45. Lin L (1989) A Concordance Correlation Coefficient to Evaluate Reproducibility. Biometrics 45: 255-68.

46. Bartko JJ, Carpenter WT J (1976) On the methods and theory of reliability. J Nerv Ment Dis 163: 307-17.

47. Landis JR, Koch GG (1977) The measurement of observer agreement for categorical data. Biometrics 33: 159-74.

48. Bland JM, Altman DG (1995) Comparing methods of measurement: why plotting difference against standard method is misleading. Lancet 346: 1085-7.

49. Aubry JF, Beaulieu L, Girouard LM, Aubin S, Tremblay D, et al. (2004) Measurements of intrafraction motion and interfraction and intrafraction rotation of prostate by three-dimensional analysis of daily portal imaging with radiopaque markers. Int J Radiat Oncol Biol Phys 60: 30-9.

50. Crook JM, Raymond Y, Salhani D, Yang H, Esche B (1995) Prostate motion during standard radiotherapy as assessed by fiducial markers. Radiother Oncol 37: $35-42$.

51.Moman MR, van der Heide UA, Kotte AN, van Moorselaar RJ, Bol GH, et al. (2010) Long-term experience with transrectal and transperineal implantations of fiducial gold markers in the prostate for position verification in external beam radiotherapy; feasibility, toxicity and quality of life. Radiother Oncol 96: 38-42.

52. DeLangen M, Hoogan M, VanderWielen G, DeBoer H, Heijimen B, Levendag P (2007) What is the ultimate fiducial marker? Radioter Oncol 84: S181-2. 
53. Morrow NV, Lawton CA, Qi XS, Li XA (2012) Impact of computed tomography image quality on image-guided radiation therapy based on soft tissue registration. Int J Radiat Oncol Biol Phys 82: e733-8.

54. Langen KM, Zhang Y, Andrews RD, Hurley ME, Meeka SL, et al. (2005) Initial experience with megavoltage (MV) CT guidance for daily prostate alignments. Int J Radiat Oncol Biol Phys 62: 1517-24.

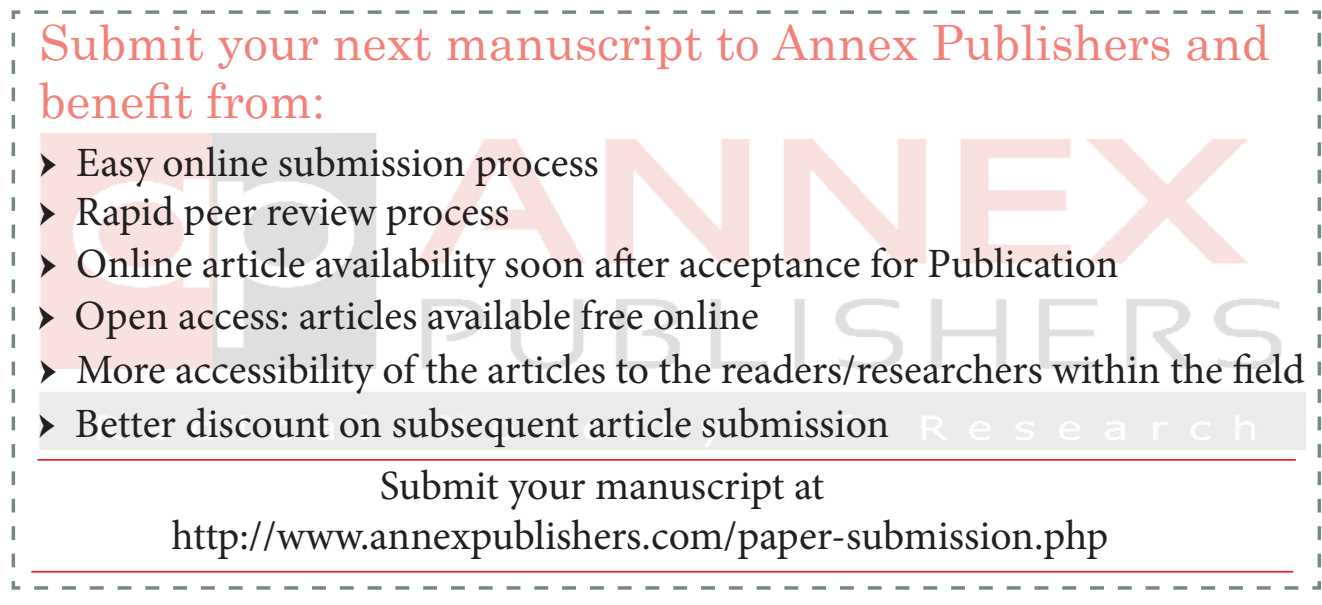

